
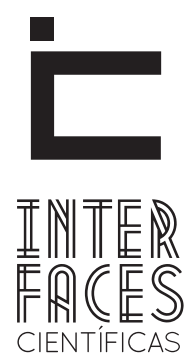

DIREITO

\title{
A FRAGMENTAÇÃO DA INFÂNCIA: UMA REALIDADE DE CRIANÇAS VÍTIMAS DA VIOLÊNCIA DOMÉSTICA
}

Acácia Gardênia Santos Lelis ${ }^{1}$

\section{RESUMO}

O presente artigo analisa a questão da violência doméstica contra crianças e adolescentes, que tem como consequência a fragmentação da infância ao acarretar a violação dos direitos humanos. A violência intrafamiliar é um fenômeno recorrente na atualidade, em todos os níveis sociais, demandando um conhecimento científico que possibilite um sistema de proteção à criança em situação de risco e de desamparo. A violência contra a criança e adolescente é fruto de uma sociedade sempre voltada a uma educação repressora, formadora indivíduos desprovidos de identidade, de liberdade e de dignidade. 0 presente trabalho enfoca o dano infância provocado pela violência doméstica e intrafamiliar, e compreende que essa acarreta fragmentação da infância com alternân-
Kátia Cristina Santos Lelis ${ }^{2}$

cia entre momentos raros da singeleza da infância e cenas marcantes de desamparo e crueldade praticados por quem tinha o dever de cuidar. Traz como conclusão teórica a importância do estudo sobre o tema que possibilita o conhecimento prévio e a identificação do problema possibilitando, assim, ações preventivas eficazes. Para a realização do presente estudo foi utilizado o método dialético, com uma abordagem qualitativa, através de pesquisa exploratória, que proporcionou aprofundamento do tema.

\section{PALAVRAS-CHAVE}

Crianças e adolescentes. Direitos humanos. Violência Doméstica. 


\section{ABSTRACT}

This paper examines the issue of domestic violence against children and adolescents, which has resulted in the fragmentation of childhood lead to the violation of human rights. Family Violence is a recurring phenomenon at present, at all social levels, requiring scientific knowledge that enables a system to protect children at risk and helplessness. Violence against children and adolescents is the result of a society always turned to a repressive education, forming individuals devoid of identity, freedom and dignity. The present study focuses on the damage caused by childhood domestic and family violence, and understands that this entails fragmentation of childhood alternating between moments of rare simplicity of childhood and striking scenes of abandonment and cruelty practiced by those who had a duty of care. Brings theoretical conclusion as the importance of the study on the subject that allows prior knowledge and the identification of the problem, thus enabling effective preventive actions. To carry out this study, the dialectical method, a qualitative approach was used, through exploratory research, which provided deeper theme.

\section{KEYWORDS}

Children and Adolescents. Human Rights. Domestic Violence.

\section{RESUMÉN}

Este artículo se examina la cuestión de la violencia doméstica contra los niños, niñas y adolescentes, lo que ha dado lugar a la fragmentación de los niños al plomo a la violación de los derechos humanos. La violencia familiar es un fenómeno recurrente en la actualidad, en todos los niveles sociales, lo que requiere el conocimiento científico que permite a un sistema para proteger a los niños en situación de riesgo y desamparo. La violencia contra los niños, niñas y adolescentes es el resultado de una sociedad siempre se dirigió a una educación represiva, formando individuos carentes de identidad, la libertad y la dignidad. El presente estudio se centra en los daños causados en la infancia por la violencia doméstica y familiar, y entiende que esto supone la fragmentación de alternancia entre momentos de la infancia, rara simplicidad de la infancia y escenas impactantes de abandono y crueldad practicada por aquellos que tenían el deber de cuidado. Trae conclusión teórica como la importancia del estudio sobre el tema, que permite el conocimiento previo y la identificación del problema, permitiendo así a las acciones preventivas eficaces. Para llevar a cabo este estudio, el método dialéctico, se utilizó un enfoque cualitativo, a través de la investigación exploratoria, que proporcionó el tema más.

\section{PALABRAS CLAVE}

Niños, niñas y adolescentes. Derechos humanos. Violencia en el hogar. 


\section{INTRODUÇ̃̃̃o}

0 presente artigo visa analisar a violência doméstica contra crianças e adolescentes, com o objetivo de desvendar as questões socioculturais que envolvem o problema, partindo-se do pressuposto de que essa decorreu da invisibilidade social da infância, perpassando pela conjuntura econômica e familiar, permeada pela pobreza e pela miséria, além dos fatores culturais que as condicionavam à completa submissão parental. A análise do problema toma como base o contexto histórico da infância, acompanhado pelo avanço social que tornou a criança sujeito de direitos, passando a um patamar de deferência social.

Inicialmente, parte-se do estudo sobre o significado da infância, por meio de um processo histórico-cultural que teve início com o sentimento da infância, no século XVII, e que percorre desde a sua invisibilidade social até a condição de sujeito de direitos na ordem jurídica, construída no século XX. Depreende-se a partir daí que o problema da violência contra a criança é complexo e que para melhor compreendê-la faz-se necessário o conhecimento da evolução histórica de proteção à criança e reconhecimento desta, como sujeito de direitos humanos.

A pesquisa foi motivada pelo conhecimento do alto índice de casos de violência doméstica contra a criança, constantemente noticiada na imprensa, e que mais comumente é praticada por quem tinha o dever ético, moral e jurídico de protegê-la. Compreender esse fenômeno possibilita a identificação prévia do problema, com a perspectiva de implementação de estratégias que sejam capazes de preveni-la.

A diversificada fonte de pesquisa utilizada para aprofundamento do tema propiciou visualizar a necessidade de um olhar para a criança como um indivíduo, que necessita de atenção, e, portanto é merecedora de proteção especial. Para a realização do presente estudo foi utilizado o método dialético, com uma abordagem qualitativa, por meio de pesquisa exploratória, que proporcionou aprofundamento do tema, sem pretender exauri-lo.

\section{A CONSTRUCĞ̃O HISTÓRICA DA PROTEÇ̃̃O À INFÂNCIA}

Bernal (2004, p. 31) afirma que "a produção historiográfica sobre crianças e adolescentes tem sido significativa, na medida em que a infância e a juventude vêm sendo estudadas com um novo tratamento conceitual e metodológico." Durante longo tempo houve uma grande resistência para reconhecer que a infância poderia ser objeto de analise e investigação cientifica. $O$ interesse pelo estudo da infância surgiu a partir da influência de estudiosos sobre a educação, pois segundo afirmam Nascimento; Branscher; Oliveira (2008), estudiosos como Phillipe Ariès, com a obra História social da infância e da família (1973), e De Mause, com a obra A evolução da infância (1991), iniciou-se um processo de construção do conhecimento da infância.

Só a partir das décadas de 1960 e 1970 é que, a partir da obra de estudiosos, em especial da área da Pedagogia e da Sociologia, passou-se a perceber a infância e a conceber a ideia de proteção, o que motivou o surgimento de várias normas de garantias de direitos e não só de repressão.

Por meio de pressões externas tais como a Declaração Universal dos Direitos da Criança, como também por organizações governamentais e não governamentais a proteção à criança passou a ter um espaço maior e melhor na sociedade. A educação e a proteção surgiram como objeto de tutela da sociedade e do Estado, e as políticas voltadas a esta temática passou então a fazer parte deste cenário. 
Este novo cenário foi percebido dentre outros registros com o Código de Menores de 1927, que representou grande avanço e pioneirismo no Brasil sendo na área jurídica o primeiro conjunto de leis voltado à tutela da criança. A distinção de mundos de crianças pobres e ricas fica bem mais evidente, e como a demanda por esta tutela aumenta significativamente. O pátrio poder e a tutela das famílias sobre os filhos eram vigiados e, condicionados, podendo ser destituídos. Vigiar e Punir tornou-se um lema e tema de discussões, bem diversificados e polêmicos.

Durante muito tempo a infância foi marginalizada pela sociedade e no seio familiar, subjugada à vontade e poderio adulto, ficando inclusive numa situação de invisibilidade social visto que não era vista como um ator social. 0 reconhecimento da infância deu-se de forma paulatina, em um processo de construção social, como afirma Ariès (1973, p. ?) que:

A família começou então a se organizar em torno da criança e a lhe dar uma, tal importância, que a criança saia do seu antigo anonimato, que se tornou impossível perdê-la ou substituí-la sem enorme dor, que ela não pôde mais ser reproduzida muitas vezes e que se tornou necessário limitar seu número para melhor cuidar dela.

A necessidade da proteção da infância era uma demanda social, não só no Brasil, mas no cenário mundial, em razão da visão discriminatória e preconceituosa das normas até então existentes, que ao invés de proteger, cuidavam mais de tutelar os desvalidos, os abandonados, os enjeitados, que assim consideravam os menores em situação irregular. Segundo Liberati (2010, p. 14), essa era a visão da proteção de crianças e adolescentes pela legislação brasileira, ao afirmar que:

As leis brasileiras anteriores à Constituição Federal de 1988 emprestavam ao menor uma assistência jurídica que não passava de verdadeiras sanções, ou seja, penas, disfarçadas em medidas de proteção; não relacionavam nenhum direito, a não ser aquele sobre a assistência religiosa; não traziam nenhuma medida de apoio à família; cuidavam da situação irregular da criança e do jovem, que na verdade, eram seres privados de seus direitos.

As normas de proteção à criança decorriam da ausência de conhecimentos sobre a infância, da importância de cada etapa de suas vidas, e de suas especiais necessidades. Só a partir dos estudos realizados sobre a infância, como exemplo do historiador francês Philippe Ariès, é que se passou a considerar as particularidades da infância, com necessidades especiais em razão de suas etapas de desenvolvimento humano. Antes, segundo Ariès (1973), as crianças não eram percebidas pela consciência social, pois eram vistas como adultos em miniatura, tendo as mesmas obrigações que esses, só tendo tratamento diferenciado nos primeiros anos de vida, enquanto dependiam do cuidado materno.

A mudança de visão sobre a infância deu-se a partir do reconhecimento de que as crianças são pessoas em desenvolvimento e sujeitos de direitos, independentemente de sua condição social. Segundo Liberati (2010, p. ?) "pela primeira vez na história das constituições brasileiras, a criança é tratada como uma questão pública, metodologia que atinge, radicalmente, o sistema jurídico".

O sistema jurídico brasileiro de proteção à criança foi realinhado a partir da Constituição Federal de 1988, e a partir da Convenção Internacional sobre os Direitos da Criança de 1989, sendo instituído no Brasil o Estatuto da Criança e do Adolescente de 1990, que traz em bojo, em especial seu artigo $6^{\circ}$ o reconhecimento de que a criança é um ser em formação, e necessita de cuidados especiais, quando assim estabelece:

$\mathrm{Na}$ interpretação desta Lei levar-se-ão em conta os fins sociais a que ela se dirige, as exigências do bem comum, os direitos e deveres individuais e coletivos, e a condição peculiar da criança e do adolescente como pessoas em desenvolvimento. 
A defesa dos direitos naturais da criança e do adolescente precisou ser normatizada, pelo reconhecimento de suas especificidades, e em razão do reconhecimento de sua vulnerabilidade. Foram assim criadas normativas internacionais para a proteção dos direitos fundamentais, tendo em vista que prescindia de garantias para sua efetivação.

\section{RECONHECIMENTO DOS DIREITOS HUMANOS DE CRIANÇAS E ADOLESCENTES}

A Declaração dos direitos da Criança de Genebra foi o primeiro documento internacional voltado a registrar e defender os direitos da criança. A proteção decorreu da atuação de Eglantyne Jebb ${ }^{3}$ junto à direção da União Internacional de Proteção à Infância, fundada em 17 de maio de 1923 (ANDREATO, 2003, apud ULTIMATO/MÃOSDADAS, 2013). Eglantyne era uma intelectual que, segundo Andreato (2003) redigiu a Declaração dos Direitos da Criança de 1924, que, após a primeira Guerra Mundial, dedicou sua vida à infância europeia, e adotou cinco princípios da Declaração de Genebra. Segundo Andrade (2010, p. 82) ela criou a Fundação de um movimento internacional de discussão de repercussões das guerras na vida das crianças, o Save the Children Fund International Union, o qual se tornou base para que, em 1923, fosse promulgada a Primeira Declaração dos Direitos da Criança, que previa, dentre outras coisas que:

À criança devem ser concedidos os meios necessários para seu desenvolvimento normal, tanto material como espiritual.

À criança que tem fome deve ser alimentada, a criança que está doente deve receber os cuidados de saúde necessários, a criança que está atrasada deve ser ajudada, a criança delinquente deve ser

3. Escocesa e irlandesa instalou-se em Cambridge, interessou-se pelas Ciências Sociais e começou um estudo sobre a situação social na cidade. Em 1913, encontrando-se nos Balcãs, em guerra, tomou consciência da miséria das crianças. Em 1919, sentiu ainda mais a necessidade de atuar a favor delas (ANDREATO, 2003 apud ULTIMATO, 2013). recuperada, e o órfão e a criança abandonada deve ser protegida e abrigada.

A criança deve ser a primeira a receber o socorro em tempos de crise ou emergência.

A criança deve ser dada todas as ferramentas para que ela se torne capaz de sustentar-se, e deve ser protegida contra toda forma de exploração.

A criança deve ser criada na consciência de que seus talentos devem ser colocados a serviço de seus semelhantes. (ULTIMATO/MAOS DADAS, 2013)

Em 1924 a criança teve um enfoque mais especifico quanto a sua proteção na Declaração de Genebra, e em 1948 seus direitos passaram a ser reconhecidos pela Declaração Universal dos Direitos Humanos 4 , e, pela Declaração dos Direitos da Criança adotada pela Assembleia Geral das Nações Unidas, em 1959, e mais recente em 1985 nas Regras de Beijing-Regras Mínimas das Nações Unidas para Administração da Justiça da Infância e da Juventude. Em 1989 surge a Convenção das Nações Unidas sobre os Direitos das Crianças, como demais tratados, visando a proteção das crianças. Para Amaro (2011, p. 37), significa uma visão diferenciada sobre as necessidades infanto-juvenis.

Antes disso, pensava-se que o sistema de proteção geral dos direitos humanos seria suficiente para a proteção dos direitos da criança e dos adolescentes, pois a eles já eram assegurados os direitos inerentes a todo ser humano. No entanto, a prática demonstrava a necessidade de um sistema especial, tendo em vista a demanda de uma proteção especifica para violação de direitos como educação, a exploração do trabalho e a violência física e psicológica praticada pela família e pela sociedade a essa vulnerável parcela da popula-

\footnotetext{
4. Escocesa e irlandesa instalou-se em Cambridge, interessou-se pelas Ciências Sociais e começou um estudo sobre a situação social na cidade. Em 1913, encontrando-se nos Balcãs, em querra, tomou consciência da miséria das crianças. Em 1919, sentiu ainda mais a necessidade de atuar a favor delas (ANDREATO, 2003 apud ULTIMATO, 2013).
} 
ção. A partir do reconhecimento dessa vulnerabilidade, o sistema jurídico internacional, foi ampliando o sistema de proteção especial, possibilitando a efetivação dos seus direitos.

Em âmbito nacional, a proteção à criança está assegurada constitucionalmente, por meio da doutrina da proteção integral adotada em seu artigo 227, que preceitua:

É dever da família, da sociedade do Estado assegurar a criança e ao adolescente, com absoluta prioridade, o direito à vida, a saúde, a alimentação, a educação, ao lazer, a profissionalização, a cultura, a dignidade, ao respeito, a liberdade e a convivência familiar e comunitária, além de colocá-los a salvo de toda forma de negligência, discriminação, exploração, violência, crueldade e opressão.

A Constituição Federal, além de garantir e assegurar os direitos devidos à infância, possibilitou uma maior conscientização da sociedade quanto a estes direitos, atribuindo-lhe ainda obrigações a assegurar o exercício desses direitos. Nos moldes da Constituição Federal, foi promulgado o Estatuto da Criança e o Adolescente (ECA), em 1990 pela Lei 8.069, com vistas a promover grandes mudanças e conquistas acerca de direitos e proteção à criança e ao adolescente. Bernal (2004, p. 25) comenta que dentre várias modificações e orientações, o ECA propõe a colocação no mesmo patamar de relevância a infância e a adolescência, com a exclusão da nomenclatura menor. Ele representa o marco da ruptura com a cultura da violência, de traço ideológico excludente.

O ECA, segundo Amaro (2011, p. 38), garante às crianças e aos adolescentes o reconhecimento dos direitos e garantias sociais, mediante os quais passam a ser atendidos e respeitados, não mais como clientes, menores ou objetos de tutela, mas como sujeitos, credores de direito.

\section{A VIOLÊNCIA CONTRA CRIANCASE ADOLESCENTES}

A família é uma instituição onde o individuo vive suas primeiras experiências de convivência, de sen- timentos, que lhe possibilita uma base de várias referências, desde afeto, hierarquia, respeito, de regras e outros aprendizados que the condicionam e prepara para a vida na sociedade como um todo.

Nas civilizações gregas e romanas a família tinha, também, outra conotação na sociedade, como política e religiosa, não se limitando a sentimentos como elo, mas outras afinidades, referências e interesses, como os econômicos, ambiente de desenvolvimento e promoção humana. A família é o núcleo natural e fundamental da sociedade e deve ser protegida pela sociedade e pelo Estado. Com a Constituição de 1988 a legitimação e o reconhecimento da família, após algumas transformações foram além do casamento e, ampliando as possibilidades de outros elos como sanguíneos e de afeto, surgindo novos modelos de entidade familiar.

A preocupação com a proteção com a família e seus membros destaca-se com o novo modelo familiar onde há a relevância do direito das crianças e adolescentes, referendado no principio da Dignidade humana, e a da prioridade absoluta dos direitos da criança.

Segundo Maciel (2010), a nova Lei n.12.010/2009 estabelece as medidas especificas de proteção, o principio da prevalência da família, significando que na promoção de direitos e na proteção da criança e do adolescente. No entanto, esse ambiente que deveria ser de proteção, muitas vezes apresenta-se como ambiente de risco, e principal locus de violação dos direitos da criança e do adolescente.

Culturalmente no Brasil, até o inicio do século XX, os castigos físicos nas escolas eram aceitos e até legitimados pelos pais e pela sociedade. Não havia limites estabelecidos aos educadores ao exigir respeito, que não era visto como uma conquista, e sim como uma imposição, ultrapassando fronteiras do bom senso, com a falta de moderação. Essa prática, pouco a pouco foi perdendo força, com o desenvolvimento social, tornando-se menos frequentes nas escolas. 
A violência por meio de ações e omissões com referência a crianças e adolescentes é antológica, não há nada de moderno, porém atual pela reincidência quanto ao abandono, espancamento, abuso sexual e outras formas e violência contra crianças e adolescentes. Percebe-se, assim, que muitas crianças e adolescentes no Brasil vivem em situação de total violência, muitas vezes fruto daqueles que deveriam tutelar seus direitos, como a liberdade, a educação, o bem estar, e a saúde.

As crianças vitimadas são as que passaram ou passam por situações da ausência do direito elementar ao exercício da cidadania, como habitação, educação, saúde, até segurança a sua sexualidade, privacidade. Notícias sobre violência intrafamiliar é cotidianamente veiculada na mídia, tanto nacional como na internacional.

Minayo (2010) comenta como o status econômico influencia na incidência da violência doméstica, no abuso de crianças e adolescentes que está presente em todas as classes sociais, mas que a sua distribuição é socialmente diferenciada. Os dados mostram que a notificação dos casos é muito maior entre os pobres, mas também há estudos sobre tendência de médicos, enfermeiros e policiais em reportar mais casos e suspeitas de casos entre as pessoas de baixa renda do que nas classes médias e abastadas (MINAYO, 2010, p. 286).

A desordem econômica ocasiona uma desordem de algumas famílias e com toda esta desestruturação e vulnerabilidade financeira, ocasiona a desestruturação das relações familiares, possibilitando a violência doméstica como fruto da fragilidade do ambiente, pois segundo Minayo (2010), a violência e o abuso existem nas várias classes sociais, mas, sua maior incidência ainda é nas classes menos privilegiadas.

A violência doméstica decorre de um histórico de concepção muito anterior à este século e com registros cruéis desde a colonização, como comenta Dourado (2009, p. 13) "os navios negreiros que traziam escravos da África, as crianças embarcadas viveram em condições de vida muito piores". Por ocasião, então, da colonização com o trafico de negros para tal, nem as crianças foram poupadas, e assim, nesse período houve registro significativo já da vulnerabilidade característica da infância.

Afirma Dourado (2009, p. 14), em sua analise sobre as crianças que crianças e adolescentes das famílias ricas se habituaram desde cedo, no Brasil, a reproduzir comportamentos autoritários e por vezes tirânicos face aos escravos adultos, ou crianças que trabalhavam em suas residências. Esse comportamento autoritário passou a ser referencial de comportamento, predominando nas famílias como modelo, e aceitos com naturalidade pela sociedade. Focault (1992, apud AMARO 2011, p. 28), afirma que diante disso surge o padrão adultocêntrico, com uma cultura de aplicação de castigos corporais como medida de correção e disciplina.

Bontempo (2010, p. 831) afirma que por muito tempo as crianças foram vistas a partir de um olhar adultocêntrico, qualificadas como seres inferiores, sem autonomia, integradas ao mundo dos adultos. Percebe-se, assim, que o ciclo de violência foi reproduzido pela sociedade, que adotou a medida de correção como forma de educação e controle, por meio de castigos corporais.

A violência doméstica é um fenômeno que não faz distinção, instala-se em classes sociais e intelectuais diversas. Distingue-se tão somente pela forma de se relacionar com esta violência. Os agentes passivos e ativos variam conforme o gênero da violência doméstica, e nem sempre há consciência da sua existência. Para Saffiotti (1997 apud AMARO, 2011, p. 105), o amor é aprendido, mas o desemparo também. A punição corporal revela que pais que foram punidos fisicamente tendem a punir fisicamente seus filhos.

A partir de uma revisão literária percebeu-se que a origem da violência decorre da reprodução de mo- 
delos. Segundo Azevedo e Guerra (2011), várias teorias procuraram levantar os fundamentos das Teorias criticas sobre a violência doméstica contra criança e adolescente como a Teoria Critica da infância, Teoria Critica da família, Teoria critica da sexualidade humana, todas para compreender o fenômeno e inacabadas pela necessidade, que abarca famílias brasileiras frutos de conflitos urbanos e rurais, e interclasses. A Teoria Critica é uma teoria social e humana na medida em que o social é uma criação humana ancorada no compromisso social com aqueles que em determinadas relações se incluem no polo oprimido, a partir do pressuposto de que toda relação social e uma relação de poder que pode exerce-se sob a forma de dominação versus subordinação (AZEVEDO e GUERRA, 2011).

As Teorias Críticas discutem sobre violência criminalidade, família, infância, sexualidade, o domínio, e possibilita segundo Azevedo e Guerra (2011), a distinção entre violência e agressão. A primeira existe no domínio da cultura e a segunda no domínio da natureza.

A infância nem sempre é vivida plenamente por todas as crianças, pois para muitos ela torna-se fragmentada pela violação dos direitos por meio da violência. Percebe-se por meio das Teorias criticas que a violência tem um histórico social, podendo assim ser por vezes ser controladas através de ações que previnam e combatam a violência. Quando do estudo dessas teorias observa-se que a violência é um fenômeno que se apresenta em varias modalidades e uma delas é a violência doméstica, a ecologia deste fenômeno é a família. Segundo Scliar (apud AZEVEDO e GUERRA, 2011, p. 245) "há um país chamado infância, cuja localização ninguém conhece ao certo. Nem todas as crianças, contudo, podem viver no País da Infância”.

A infância vitima de violência é tão variada quanto os meios e modos de violentar crianças e adolescentes, embora toda violência seja social, essas crianças são os filhos da violência, denominados de social em sentido amplo (AZEVEDO; GUERRA, 2011, p. 246).
Percebe-se, assim que muitas crianças têm fragmentadas à sua infância, alternando momentos raros de singeleza da infância com cenas cruéis de violência e terror, significando que ser criança, nem sempre significa ter infância. São vítimas do desamor, de uma sociedade doente e acometida de falta de tolerância e de solidariedade, e seus principais algozes são aqueles que lhes deviam garantir amor e proteção.

\section{A VIOLAÇ̃̃O DOS DIREITOS HUMANOS NA VIOLÊNCIA CONTRA A CRIANÇA}

Numa situação ou relação onde exista violência não há vencedores e perdedores, todos perdem, e sempre há vitimas, alguns, além de vitimados são vitimadores, o castigo, o sofrimento, a dor é coletiva. A violência permeia a sociedade, e a prática dela se aprende muitas vezes nas relações primárias, ou seja, na primeira sociedade em que se conhece que é a família, e nessa convivência se aprende e se repete modelos de violência baseado numa cultura violenta e perversa.

A violação de direitos fundamentais da criança em razão da violência doméstica, configurada na violação dos direitos à saúde, seja no aspecto físico ou psicológico, constitui-se, também, na violação de sua dignidade. Dignidade Humana para Sarlet (1988, p. 51-52) “não pode ser definida de forma fixista, ainda mais quando se verifica que uma definição dessa natureza não harmoniza com o pluralismo e a diversidade de valores que se manifestam nas sociedades democráticas contemporâneas".

Na definição de Sarlet (1998, p. 73),

[...] temos por dignidade da pessoa humana a qualidade intrínseca e distintiva reconhecida em cada ser humano que o faz merecedor do mesmo respeito e consideração por parte do Estado e da comunidade, implicando, neste sentido, um complexo de direitos e deveres fundamentais que assegurem a pessoa tan- 
to contra todo e qualquer ato de cunho degradante e desumano, como venham a the garantir as condições existenciais mínimas para uma vida saudável, além de propiciar e promover sua participação ativa e co-responsável nos destinos da própria existência e da vida em comunhão com os demais seres que integram a rede da vida.

A prevenção de combate à violação da dignidade da criança é dever da família, do Estado e da Sociedade, conforme estabelece o artigo 227 da Constituição Federal, que traz de forma explícita a doutrina da proteção integral. Amin (2010) comenta sobre a doutrina proteção integral, espelho segundo ela espelho do princípio da dignidade da pessoa humana para crianças e adolescentes.

Amin (2010) ainda comenta sobre os Princípios gerais que norteiam o ECA que são:

- Princípio da prioridade absoluta;

- Princípio do melhor interesse;

- Princípio da municipalização

Dando maior enfoque e atenção ao especifico da área de atuação ou que respeitem os institutos próprios que versam sobre medidas de proteção estabelecidas no parágrafo 100 do ECA. 0 principio da prioridade absoluta, objetiva realizar a proteção integral, assegurando primazia que facilitará a concretização dos direitos fundamentais enumerados no artigo 227 , caput da Constituição da República e remunerados no capitulo $4^{\circ}$ do Eca (AMIN, 2010, p. 19-20).

A primazia das necessidades da criança e do Adolescente deve ser referência para efetivar por meio da interpretação da lei e da efetivação dos princípios que formam pilar de referência que asseguram, concretizando o princípio do melhor interesse. A privação o bem estar da criança e dos adolescentes viola os direitos humanos e consequentemente o da infância em que não é levado em conta a Dignidade da pessoa humana e a vulnerabilidade da infância.

\section{CONCLUSÃO}

Com um histórico de maus tratos de sujeitamento de direitos das crianças e adolescentes, percebem-se componentes desafiadores e precursores da infância acerca da Violência contra Criança e Adolescentes.

Modelos antagônicos de uma pedagogia violenta não consegue ser rompido de maneira abrupta, mas num processo de evolução e comprometimento da sociedade e do Estado. Valores culturais e éticos hão de ser colocados em discussão para quem sabe ser refletidos com esperança de uma mudança social, jurídica e humanitária.

A violência foi, durante muito tempo, concebida como o padrão de disciplinamento e educação e sem preconceito social e ou racial, passeia por todas as classes, gêneros e raças, dificultando então seu combate, assim prevalecendo a prevenção por meio da educação e formação para educar.

A observação de uma postura de poder de polícia e autoridade do adulto seja ele com que elo legal ou afetivo que obsta e neutraliza sua função maior que seria o zelo e a tutela da criança e do adolescente. A coisificação da infância foi durante muito tempo aceita como a referência e modelo, legitimando, portanto, um comportamento de subserviência da criança diante dos seus pares, a quem incumbiria o dever de protegê-los e garantir o seu bem-estar.

A violência doméstica é um fenômeno que extrapola limites nacionais, e, negar sua complexidade é omitir-se quanto a sua existência e espaço que ocupa no eixo intrafamiliar. 0 agente passivo deste fenômeno é sempre a criança e ou o adolescente, e o ativo em sua maioria o adulto, com relação consanguínea ou não, mas que assume um poderio assegurado muitas vezes pelo econômico. 
A vulnerabilidade da criança fomenta a proliferação da violência, sendo potencializada com a aceitação da sociedade e até do Estado, de forma muitas vezes velada, mas cruel. Essa violência fragmenta a fase da infância, tornando inóspitos os direitos que a ela são peculiares.

A cultura da violência habita a sociedade e as famílias de maneira secular no Brasil, mais especificamente é concebida desde os jesuítas, na verdade percebe-se não só a concepção com naturalidade da violência como forma de pedagogia e disciplinamento, como um clamor social para sua utilização. 0 grande desafio para combater o problema é o bloqueio deste ciclo, pois há as evidências demonstram que adultos, que sofreram violência na infância, tendem a reproduzi-la com naturalidade.

Os avanços da modernidade de nada adiantam se o abandono, o desamparo, e as atitudes cruéis contra crianças e adolescentes tornam-se atos rotineiros e naturalizados pela sociedade. A violência doméstica e intrafamiliar contra crianças e adolescentes precisam ser assumidas, como questão de ordem pública, para que possa ser identificada, e que seja objeto de politicas públicas eficazes capazes de preveni-la e erradicá-la da sociedade, permitindo o exercício pleno da infância.

\section{REFERÊNCIAS}

AMARO, Sarita. Crianças vítimas de violência, das sombras do sofrimento à genealogia da resistência: uma nova teoria científica. 2.ed. Porto Alegre: EDIPUCRS, 2011.

AMIN, Andrea Rodrigues. Evolução histórica do direito da criança e do adolescente. In Maciel, Katia Regina Ferreira Lobo Andrade (coord.). Curso de Direito da Criança e do adolescente: aspectos teóricos e práticos. 3.tiragem. Rio de Janeiro: Lumen Juris, 2010, p.3-10.
ANDRADE, Anderson Pereira de. A Convenção Sobre os Direitos da Criança em seu Décimo Aniversário: Avanços, Efetividade e Desafios. Revista Igualdade, 2003. Disponível em: <http://www.escolamp.org.br/ ARQUIVOS/15_01.pdf>. Acesso em: 11 nov. 2013.

ANDRADE, Lucimary Bernabé Pedrosa de. Direitos da infância: da tutela e proteção à cidadania e educação. São Paulo: Unesp; Scielo books, 2010.

ANDREATO, Elifas. Ultimato, mãos dadas. A história da heroína que criou a Declaração dos Direitos da Criança. ALMANAQUE BRASIL, janeiro, 2003. Disponível em: <http://ultimato.com.br/sites/ maosdadas/2013/01/22/a-historia-da-heroina-que-criou-a-declaracao-dos-direitos-da-crianca/>. Acesso em: 1 dez. 2013.

ARIĖS, Philippe. História social da criança e da família. 2.ed. Tradução de Dora Flaksman. Rio de Janeiro: Afiliada, 1973.

ARIĖS, Philippe. Historia social da criança e da família. Edittions Seuil Maisons Laffitt. 1914 -1984, tradução 1973 LTC- Livros Técnicos Nacional -GEN Grupo Editorial Nacional, 1978.

AZEVEDO, Maria Amélia e GUERRA, Viviane N. de A. Infância e Violência Doméstica: Fronteiras do conhecimento. 6.ed. São Paulo: Cortez, 2011.

BASTOS, Juarez Gomes Pereira. Conselho Tutelar Mediador de uma Transição Cultural "Em contradição com a visão que os demais agentes de garantia de direitos de criança e de adolescente têm dele". Rio de Janeiro, setembro de 2010.

BERNAL, Elaine Marina Bueno. Arquivos do Abandono. São Paulo: Cortez, 2004.

DOURADO, Ana Cristina Dubeux. História da infância e direitos da criança. In: Salto para o futuro. Ano XIX, n.10, TV Escola, 2009. 
LAMENZA, Francimar. Os Direitos Fundamentais da Criança e do Adolescente e a discrionariedade do Estado. São Paulo: Manole, 2011.

LIBERATI, Wilson Donizeti. Direito da Criança e do Adolescente. 4.ed. São Paulo: Rideel, 2010.

LIMA, Fausto Rodrigues e SANTOS, Claudiene. Violência Doméstica Vulnerabilidade e Desafios na Intervenção Criminal e Multidisciplinar. 2. Tiragem. Rio de Janeiro: Lumen Juris, 2010

MACIEL, Kátia Regina Ferreira Lobo Andrade (Coord.). Curso de Direito da Criança e do Adolescente: Aspectos Teóricos e Práticos. 4.ed. IBDFAM. Rio de janeiro: Lumen Juris, 2010.

MARCILIO, Maria Luiza. História Social da Criança Abandonada. São Paulo: Hucitec,1998.

MINAYO, Maria Cecília - O que você ainda não sabe sobre violência contra a criança. In: Revista Crescer em Família. São Paulo: Globo, 2010.
NASCIMENTO, Cláudia Terra do; BRANCHER, Vantoir Roberto; OLIVEIRA, Valeska Fortes. A construção Social do Conceito de Infância: algumas interlocuções históricas e sociológicas. Revista Contexto \& Educação. Ano 23. n.79. Jan/jun. Rio Grande do Sul: Unijui, 2008, p.47-63. Disponível em: <https://www.resvistas.unijui.edu.br/index.php/contextoeducação/article/view/1051/802>. Acesso em: 1 dez. 2013.

\section{Revista Brasileira de Historia e Ciências Sociais.} Disponível em <www.rbhcs.com>. ISSN - 21753423. Francisvaldo Alves Nunes. INCOMPLETA?

SARLET, Ingo Wolfgang. Dignidade da Pessoa Humana: na Constituição de 1988. 9.ed. Ver. Atual. 2.tir. Porto Alegre: Livraria do Advogado, 2012.

SARMENTO, Daniel, IKAWA, Daniela e PIOVESAN, Flavia. Igualdade, Diferença e Direitos Humanos. 2.tiragem. Rio de Janeiro: Lumen Juris, 2010.

VIGOTSKI, Lev Semenovich, 1896-1934. Psicologia Pedagógica. Trad. Do russo e introdução de Paulo Bezerra. 2.ed. São Paulo: Martins Fontes, 2004.

1. Advogada, Mestranda em Direito pela PUC/PR do Programa de Direito Econômico e Socioambiental, linha de Sociedade e Direito, Especialista em Direito Processual pela Universidade Federal de Sergipe, professora do Curso de Direito e Serviço Social da Universidade Tiradentes - Se, professora do curso de Direito da Faculdade Pio Décimo, Presidente da Comissão Estadual de gênero e Violência Doméstica do Instituto Brasileiro de Direito de Família-IBDFAM/SE, membro substituta do Conselho Estadual dos Direitos da Mulher do Estado de Sergipe- CEDM, integrante da Comissão de Defesa dos Direitos da Mulher da OAB/SE, integrante do grupo de pesquisa Justiça, Democracia e Direitos Humanos da PUC/PR e do grupo de pesquisa sobre a mulher e a família da Faculdade Tiradentes. E-mail: aglelis@infonet.com.br.
2. Graduada em Direito pela Faculdade Pio Décimo, e Especialista em E-mail: katitalelis@ig.com.br. 